\title{
High-Specific-Capacity and High-Performing Post-Lithium-Ion Battery Anode over 2D Black Arsenic Phosphorus
}

\author{
Nabil Khossossi, Deobrat Singh, Amitava Banerjee, Wei Luo, Ismail Essaoudi, Abdelmajid Ainane, \\ and Rajeev Ahuja*
}

Cite This: ACS Appl. Energy Mater. 2021, 4, 7900-7910

Read Online

\section{ACCESS | Lill Metrics \& More | 回 Article Recommendations | (1) Supporting Information}

ABSTRACT: Nowadays, secondary batteries based on sodium $(\mathrm{Na})$, potassium $(\mathrm{K})$, and magnesium $(\mathrm{Mg})$ stimulate curiosity as eventually high-availability, nontoxic, and eco-friendly alternatives of lithium-ion batteries (LIBs). Against this background, a spate of studies has been carried out over the past few years on anode materials suitable for post-lithium-ion battery (PLIBs), in particular sodium-, potassium- and magnesium-ion batteries. Here, we have consistently studied the efficiency of a 2D $\alpha$-phase arsenic phosphorus $(\alpha$-AsP) as anodes through density functional theory (DFT) basin-hopping Monte Carlo algorithm (BHMC) and ab initio molecular dynamics (AIMD) calculations. Our findings show that $\alpha$-AsP is an optimal anode material with very high stabilities,

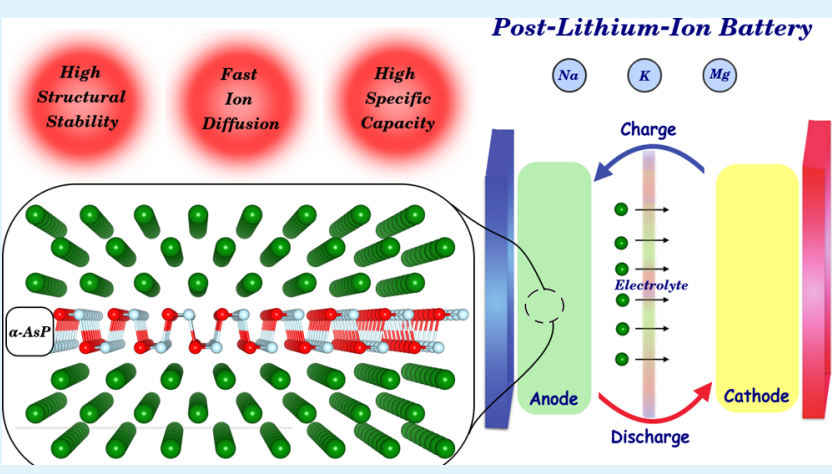
high binding strength, intrinsic metallic characteristic after $(\mathrm{Na} / \mathrm{K} /$

$\mathrm{Mg}$ ) adsorption, theoretical specific capacity, and ultralow ion diffusion barriers. The ultralow energy barriers are found to be 0.066 $\mathrm{eV}(\mathrm{Na}), 0.043 \mathrm{eV}(\mathrm{K})$, and $0.058 \mathrm{eV}(\mathrm{Mg})$, inferior to that of the widely investigated MXene materials. During the charging process, a wide $\left(\mathrm{Na}^{+} / \mathrm{K}^{+} / \mathrm{Mg}^{2+}\right)$ concentration storage from which a high specific capacity of $759.24 / 506.16 / 253.08 \mathrm{mAh} / \mathrm{g}$ for $\mathrm{Na} / \mathrm{K} / \mathrm{Mg}$ ions was achieved with average operating voltages of $0.84,0.93$, and $0.52 \mathrm{~V}$, respectively. The above results provide valuable insights for the experimental setup of outstanding anode material for post-Li-ion battery.

KEYWORDS: post-lithium-ion batteries, density functional theory calculations, sodium-ion, potassium-ion, magnesium-ion, anodes, 2D AsP, high specific capacity

\section{INTRODUCTION}

Due mainly to various outstanding electrochemical features, such as a great energy density, high efficiency, large insertion potential, and exceptional cycle efficiency, lithium-based ion batteries have been widely and fruitfully integrated in electronic devices including mobile phones, tablets, laptops, and so on. ${ }^{1-4}$ During the last years, in parallel with the ongoing improvement of Li-ion battery performance, their adaptability has broadened to include both small- and large-scale applications, notably in electric vehicles and smart grids. 5,6 However, the widespread implementation of electrochemical energy storage systems based on the lithium-ion battery has been hampered by safety issues and by its relatively high price, due to its rarity in the earth's crust. ${ }^{7,8}$ Therefore, post-Li-ion batteries (PLIBs) were recognized to be the advanced and promising green generation of electrochemical energy storage devices, especially, Na-, ${ }^{9} \mathrm{~K}-{ }^{10}$ and Mg-ion batteries, ${ }^{11,12}$ owing to their availability, adequate insertion potential, and high safety. $^{13-15}$

Importantly, it is noteworthy to point out that regardless of the type of rechargeable batteries, Li-ion or post-Li-ion batteries, the physical, chemical, and electrochemical proper- ties of the material utilized in both the anodes and cathodes, such as outstanding cyclability, high electronic conductivity, and great specific capacity, is a vital and decisive element in the evaluation of the battery's performance. ${ }^{16-20}$ Despite the thorough exploration of a wide variety of positive electrode materials, the state of the art on negative electrode materials has been considerably hampered. ${ }^{21-29}$ Many different materials were experimentally and theoretically demonstrated to be suitable candidates for $\mathrm{Li}$-ion batteries, such as group IVA and VA compounds-based alloying and dealloying, ${ }^{30-34}$ nanostructured materials, ${ }^{35}$ carbon-based materials, ${ }^{6,36,37}$ and metal oxide materials. ${ }^{38}$ However, these C-based compounds such as graphite were significantly upgraded with respect to both safety and cycling efficiency, and they proved inadequate for use as an anode material to support post-Li-ion batteries.

Received: May 3, 2021

Accepted: August 3, 2021

Published: August 11, 2021 

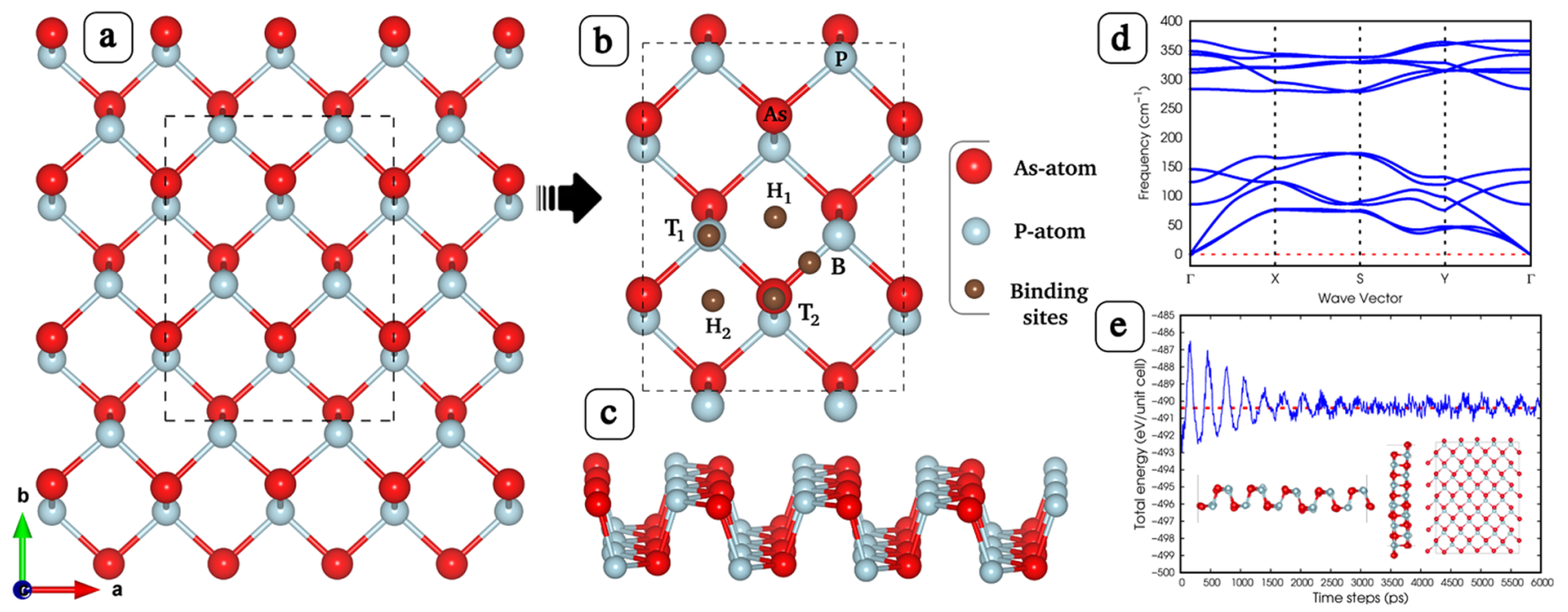

Figure 1. $(\mathrm{a}-\mathrm{c})$ Schematic structures of top and side views of a free-standing $\alpha$-AsP monolayer. The possible adsorption sites are shown on the $\alpha$ AsP surface with a brown spherical shape. Dynamic and thermal stabilities of $2 \mathrm{D}$ black AsP monolayer, (d) phonon dispersion pattern along the $k$ vectors with high symmetry, and (e) variation in total energy over 12 ps during the ab initio molecular dynamic simulation at $300 \mathrm{~K}$ with the geometric snapshot of the structure at the end of the MD simulation.

Consequently, identifying a good anode material with high specific capacity and ultralow ion diffusion barriers for post-Liion batteries becomes an essential challenge.

One of the most effective approaches consists of reducing the dimensionality of the anode materials. Notably, twodimensional (2D) materials with high surface area and outstanding features have the potential to significantly enhance the kinetics of $\mathrm{Na}-, \mathrm{K}-$, and Mg-ion transfer. ${ }^{39,40}$ For example, phosphorene and arsenene monolayers were computationally suggested as a suitable and highly efficient electrode material for PLIBs offering exceptional theoretical specific capacity and a low diffusion barrier. ${ }^{41-44}$ However, the instability of both of these monolayers under normal conditions severely restricts their use in PLIB applications. ${ }^{45-47}$

In addition, based on the outstanding features of the already available black- and blue-phase phosphorus and arsenic materials, the new $\alpha$-AsP and $\beta$-AsP materials provide the opportunity to further explore novel materials with enhanced physical properties. More recently, a multilayered black $\mathrm{As}_{1-n} \mathrm{P}_{n}$ with $(0.7 \leq n \leq 1)$ has been synthesized experimentally and appears to be an $\alpha$-P-like structure, where some $\mathrm{P}$ atoms are replaced by $\mathrm{A}$ atoms. ${ }^{48,49}$ However, its lattice constant is a little higher than $\alpha$-P, due to the slight outward displacement of As atoms out of the unit cell. Such a flexible and unique structure presents it as a prospective applicant for high-performance energy conversion and storage systems. A number of recent computational and experimental studies have demonstrated that $2 \mathrm{D} \alpha$-AsP may be a potentially suitable material for use as a donor material for excitonic solar cells (XSC), an excellent alternative candidate for optoelectronic, and a candidate for digital and radio frequency (RF) applications. To date, from what we know there is no investigation into the applicability of this $2 \mathrm{D} \alpha$-AsP monolayer as battery electrodes for energy storage systems. ${ }^{50-53}$

Here, we investigate for the first time the applicability of the $\alpha$-AsP monolayer for post-Li-ion battery electrode. Based on DFT calculations. We started by rechecking the structural, dynamical, and thermal stability of the $\alpha$-AsP monolayer. After that, the binding energies of $\mathrm{Na}, \mathrm{K}$, and $\mathrm{Mg}$ atoms at several suitable adsorption sites on the $\alpha$-AsP monolayer were computed. The deformation charge density after the adsorption of single $\mathrm{Na}, \mathrm{K}$, and $\mathrm{Mg}$ atoms was calculated. The equilibrium voltage and theoretical capacity were calculated by investigating the effect of $(\mathrm{Na} / \mathrm{K} / \mathrm{Mg})$ concentration on both sides of the monolayer. The diffusion path of single $\mathrm{Na}^{+}, \mathrm{K}^{+}$, and $\mathrm{Mg}^{2+}$ in the $\alpha$-AsP monolayer is along zigzag/armchair directions and in the bulk AsP along the zigzag directions. And finally, the biaxial strain and its effect on the adsorption and diffusion barrier were investigated. A thorough comparison to other currently available $2 \mathrm{D} \alpha$-phase materials recently predicted for battery electrode reveals that $\alpha$-AsP can be distinguished as a potentially attractive addition to post-Li-ion negative electrode materials.

\section{RESULTS AND DISCUSSION}

2.1. Structural, Stability, and Electronic Properties of the $\boldsymbol{\alpha}$-AsP Monolayer. The atomic structures of a nonplanar $\alpha$-AsP monolayer are presented in Figure 1a-c, which shows a honeycomb-type structure. This structural shape is similar to black phosphorene. ${ }^{54}$ In the case of the $\alpha$-AsP monolayer, we have replaced a single $\mathrm{P}$ atom with As atom. ${ }^{55}$ The nonplanar structures of the $\alpha$-AsP monolayer show dynamic stability, and each $\mathrm{P}$ and $\mathrm{As}$ atom bonded with three As/P atoms. As a consequence, the nonplanar $\alpha$-AsP monolayer shows the formation of $\mathrm{sp}^{2}$ - and $\mathrm{sp}^{3}$-hybridized chemical bonds. The optimized lattice parameters $a$ and $b$ are 3.505 and $4.69 \AA$, which is consistent with previous literature, ${ }^{51-53,55}$ while the lattice parameters of black phosphorene are 3.32 and $4.58 \AA$, respectively. ${ }^{56}$ We can see that the single-atom replacement significantly increased the lattice parameters. The values of bond length between As and $\mathrm{P}$ are 2.378-2.385 $\AA$ and the buckling height is $2.35 \AA$. In the next section, we discuss the absorption of different metal atoms on the $\alpha$-AsP monolayer surface. Figure $1 \mathrm{~b}$ (right) shows the possible positions of different $(\mathrm{Na} / \mathrm{K} / \mathrm{Mg})$ atoms with a brown spherical shape.

Now, we will discuss the structural stability of the $\alpha$-AsP monolayer. The structural stability is confirmed by thermodynamic stability, which is examined by their cohesive energies and their phonon dispersion spectra (Figure 1d). The cohesive energy of $\alpha$-AsP is described by 

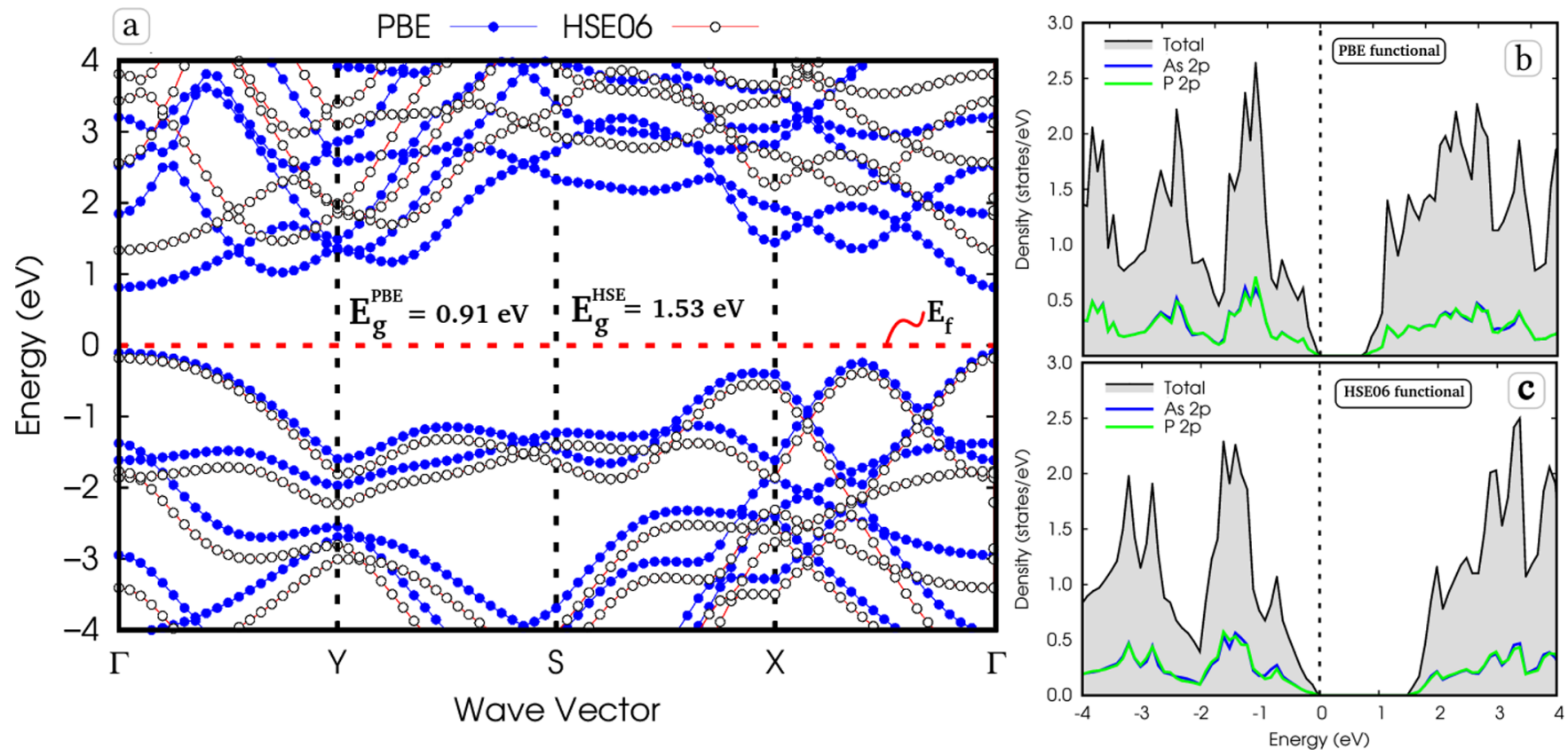

Figure 2. Electronic properties of 2D $\alpha$-phase AsP monolayer. (a) Band structure of $\alpha$-AsP with GGA-PBE (blue color) and HSE06 (white-black color) hybrid functional calculations. The Fermi level is set to zero, and the eigenvalue band gaps are indicated in eV. (b, c) Total and partial density of states of $\alpha$-AsP at the GGA-PBE and HSE06 levels of theory, respectively. The Fermi level is set at zero.

$$
E_{\mathrm{C}}=\left(E_{\text {total }}-2 E_{\text {As }}-2 E_{\mathrm{P}}\right) / 4
$$

where $E_{\text {total }}, E_{\mathrm{As}}$, and $E_{\mathrm{p}}$ represent the total energies of the $\alpha$ AsP monolayer, an individual arsenic atom, and an individual phosphorus atom. The $E_{\mathrm{C}}$ of the $\alpha$-AsP monolayer is -5.25 $\mathrm{eV} /$ atom. The magnitude of $E_{\mathrm{C}}$ is larger than that of the cohesive energy of $\beta$-P $(-3.477 \mathrm{eV} / \text { atom })^{57}$ and gray arsenic monolayer $(-2.84 \mathrm{eV} /$ atom $) .{ }^{58}$ The result of cohesive energies also indicates that the $\alpha$-AsP structures are energetically stable. Also, the thermal stability of the $\alpha$-AsP monolayer was investigated by the AIMD calculations. A $5 \times 5 \times 1$ supercell was used during the simulation at the temperature of $300 \mathrm{~K}$. Figure 1e shows the snapshot of the $\alpha$-AsP monolayer at the end of 12 ps molecular dynamic simulation. The snapshot shows that the $\alpha$-AsP monolayer can maintain its structural integrity throughout the simulation in which there is no breaking of bond between As-P and also very small fluctuation appears in the vertical direction of the sheet. According to that, the simulated result reveals that the $\alpha$-AsP monolayer may have good thermal stability at $300 \mathrm{~K}$. Additionally, the kinetic stability of the $\alpha$-AsP monolayer is confirmed by phonon spectra along the high-symmetry points in the $\mathrm{BZ}$ as shown in Figure $1 \mathrm{~d}$. There is no imaginary frequency appearing in the phonon dispersion profile, which suggests the good kinetic stability of the $\alpha$-AsP monolayer.

To further understand the nature of the $\alpha$-AsP monolayer, we have calculated the electronic band structures as shown in Figure 2a. For the comparison of electronic band gap, we have used two different exchange correlation functionals such as PBE-GGA and hybrid functional with a standard parameter (HSE06). The electronic band structure shows the direct band gap at $\Gamma$ of 0.91 and $1.51 \mathrm{eV}$ by PBE-GGA and HSE06 functionals, respectively. It was seen that the electronic band lines in the electronic band structure shifted downward/ upward from the Fermi level in the valence band maximum (VBM) and conduction band minimum (CBM). Moreover, we have investigated the projected density of states (PDOS) to see the contribution of orbitals near the Fermi level as shown in Figure $2 \mathrm{~b}, \mathrm{c}$. The p-states of As and $\mathrm{P}$ atoms have almost the same contribution near the Fermi level. It means that the pstates of both atoms are strongly hybridized in VBM and CBM. According to that, $\mathrm{p}$-states of both atoms are responsible for making the electronic band gap (i.e., semiconducting nature) of the $\alpha$-AsP monolayer.

2.2. Binding Strength of Single $(\mathrm{Na} / \mathrm{K} / \mathrm{Mg})$ Atom on the $\boldsymbol{\alpha}$-AsP Monolayer. To pursue our studies, the first step in examining the binding strength of a single $(\mathrm{Na} / \mathrm{K} / \mathrm{Mg})$ atom on the $\alpha$-AsP monolayer consists mainly of selecting the strongest suitable binding site. Assuming the symmetry of the geometrical structure, we have examined a total of five binding sites, as depicted in Figure $1 \mathrm{~b}$. The starting binding sites are classified as three different classes: (i) the top site $\left(\mathrm{T}_{1}\right.$ and $\left.\mathrm{T}_{2}\right)$ : positioning on the top of any $\mathrm{P}$ and As atom based on crystal symmetry; (ii) the hollow site $\left(\mathrm{H}_{1}\right.$ and $\left.\mathrm{H}_{2}\right)$ : locating above a triangular neighboring unbonded As and $\mathrm{P}$ atoms, respectively; and (iii) the bridge site: positioning between As and $\mathrm{P}$ atoms. Additionally, owing to the mirror-symmetrical nature of the $\alpha$ AsP monolayer, it is sufficient just to put the adsorption atoms on one side of the $\alpha$-AsP monolayer.

The principle that consists of recognizing the privileged binding site of $\mathrm{Na}, \mathrm{K}$, and $\mathrm{Mg}$ atoms on the $\alpha$-AsP surface is derived according to the binding strength equation given above by means of a large $2 \times 2 \times 1$ supercell to prevent the interaction of adjacent adatoms

$$
E_{\mathrm{b}}=E_{(\mathrm{Na} / \mathrm{K} / \mathrm{Mg}) @ \mathrm{AsP}}-E_{\mathrm{AsP}}-E_{\mathrm{Na} / \mathrm{K} / \mathrm{Mg}}
$$

wherein $E_{(\mathrm{Na} / \mathrm{K} / \mathrm{Mg}) @ \mathrm{AsP}}$ and $E_{\mathrm{AsP}}$ correspond to the total energies of the $\alpha$-AsP in the presence and absence of adsorbed $\mathrm{Na}, \mathrm{K}$, and $\mathrm{Mg}$ ions, and $E_{\mathrm{Na} / \mathrm{K} / \mathrm{Mg}}$ represents the average energy of $\mathrm{Na}, \mathrm{K}$, and $\mathrm{Mg}$ atoms in bulk reference state. By definition, more negative the binding strength is, more stable the binding configuration is, indicating the scattering distribution of the adsorbed $\mathrm{Na} / \mathrm{K} / \mathrm{Mg}$ atoms instead of 
Table 1. Adsorption Energies of $(\mathrm{Na} / \mathrm{K} / \mathrm{Mg})$ Atoms Adsorbed at Five Different Sites of the AsP Monolayer (Figure 1$)^{a}$

$\begin{array}{ccccccc}\mathrm{Na} / \mathrm{K} / \mathrm{Mg} & \text { binding site } & \text { binding energy }(\mathrm{eV}) & \text { minimal } d_{\mathrm{AM}-\mathrm{As}}(\AA) & \text { minimal } d_{\mathrm{AM}-\mathrm{P}}(\AA) & \text { structural distortion }(\AA) & \text { bader charge } \\ \mathrm{Na} & \mathrm{H}_{1} & -1.59 & 2.88 & 2.89 & 0.049 & 0.782 \\ \mathrm{~K} & \mathrm{H}_{1} & -1.78 & 3.20 & 3.22 & 0.047 & 0.816 \\ \mathrm{Mg} & \mathrm{H}_{1} & -0.91 & 2.77 & 2.81 & 0.059\end{array}$

${ }^{a}$ Also listed are the minimal bonding distance of the $(\mathrm{Na} / \mathrm{K} / \mathrm{Mg})$ atoms and the $(\mathrm{Na} / \mathrm{K} / \mathrm{Mg})$-to-AsP charge transfer $\Delta \rho$ calculated from the Bader analysis algorithm. Both minimal bonding distance and $\Delta \rho$ are calculated for $(\mathrm{Na} / \mathrm{K} / \mathrm{Mg})$ atoms adsorbed at $\mathrm{H}$ sites.

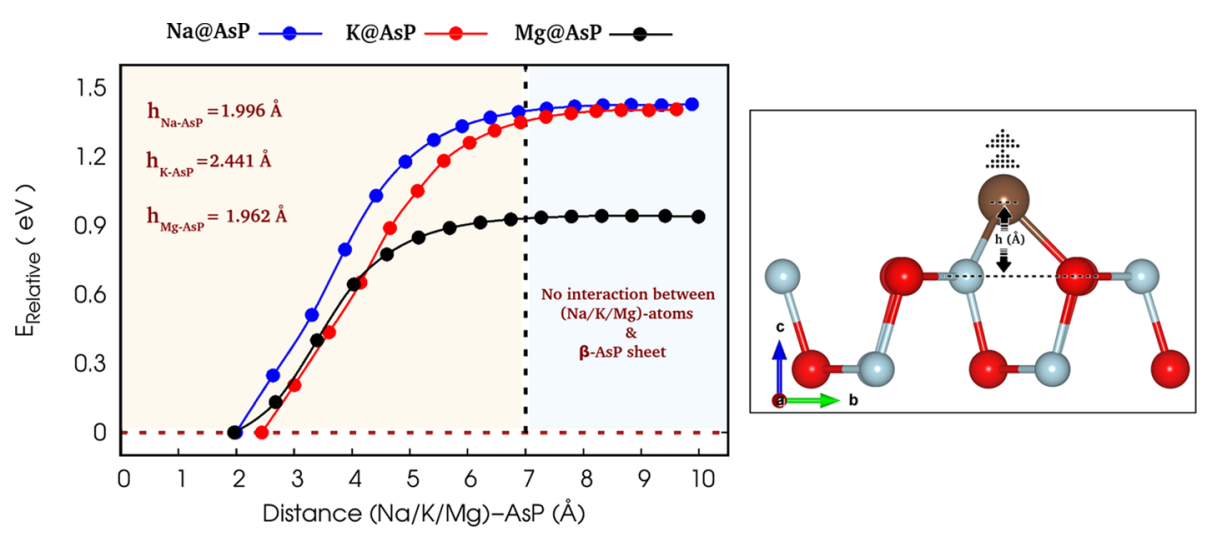

Figure 3. Variation in the total potential energy of the $(\mathrm{Na} / \mathrm{K} / \mathrm{Mg})$ atom on $\alpha$-AsP sheet as a function of the $(\mathrm{Na} / \mathrm{K} / \mathrm{Mg})-\mathrm{AsP}$ distance.

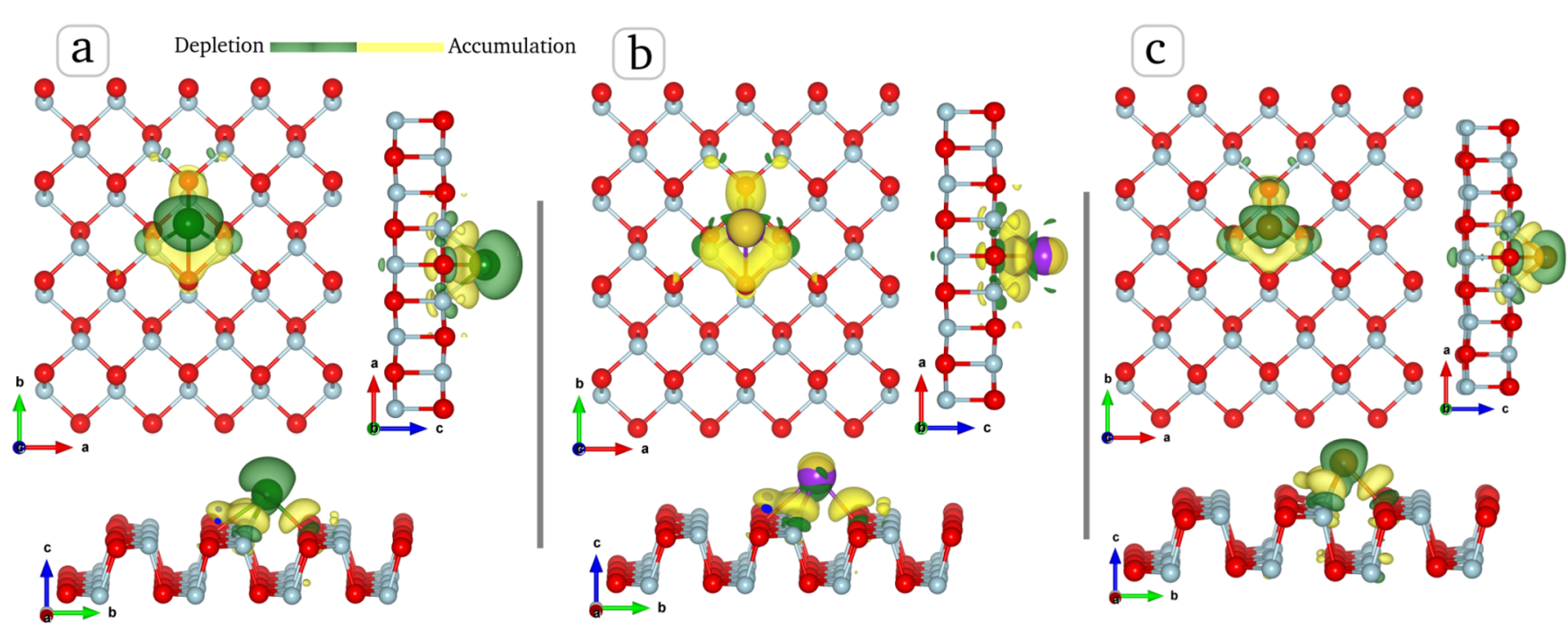

Figure 4. Charge density difference of single $\mathrm{Na}(\mathrm{a}), \mathrm{K}(\mathrm{b})$, and $\mathrm{Mg}$ (c) adsorbed at the most favorable binding site ( $\mathrm{H}$-site) on the $\alpha$-AsP monolayer. The green and yellow colors refer to the depletion and accumulation of charge, respectively. The isovalue is considered to be $0.0015 \mathrm{e} /$ $\AA^{3}$.

their clustering, therefore avoiding the issues arising from the formation of metal dendrites or metal clusters (e.g., short circuits) during the charge/discharge process. Table 1 summarizes the computed binding strength at the most stable binding site configuration and the detailed structural parameters with charge transfer after single $\mathrm{Na} / \mathrm{K} / \mathrm{Mg}$ adsorption. It is shown that the $\alpha$-AsP sheet as anode exhibits a high affinity toward all metal atoms considered with negative $E_{\mathrm{b}}$ values of $-1.59,-1.78$, and $-0.91 \mathrm{eV}$ for $\mathrm{Na}, \mathrm{K}$, and $\mathrm{Mg}$, respectively, which are greater than that for $(\mathrm{Na} / \mathrm{K} / \mathrm{Mg})$ adsorption energy of some previously explored $\alpha$-phase materials, such as $\mathrm{Na}$ adsorption on $\alpha$-SiS and $\alpha$-SiSe monolayers $(-0.94$ and $-0.43 \mathrm{eV}),{ }^{59} \alpha$-GeS monolayer (with $1.351 / 1.430 \mathrm{eV}$ for $\mathrm{Na} / \mathrm{K}$ ) ${ }^{60} \alpha$-GeSe monolayer (with $-1.25 /-1.36 \mathrm{eV}$ for $\mathrm{Na} / \mathrm{K}),{ }^{61}$ and the $\mathrm{Mg}$ adsorption on black phosphorene surface $(-1.09 \mathrm{eV}){ }^{62}$ implying that the binding of $\mathrm{Na} / \mathrm{K} / \mathrm{Mg}$ metals to the $\alpha$-AsP surface occurs as an exothermic process. The minimal binding height between the metal atoms and As/P atoms on the surface of $\alpha$-AsP is inversely proportional to the atomic radius and to the electronegativity of the metal atoms and follow the sequence of $\mathrm{K}>\mathrm{Na}>\mathrm{Mg}$. In addition, the adsorption of single $(\mathrm{Na} / \mathrm{K} /$ $\mathrm{Mg}$ ) atom induces no significant structural distortion on the $\alpha$ AsP surface. The $z$-direction variation of $\mathrm{P}$ atoms relative to their starting position by adsorption of $\mathrm{Na} / \mathrm{K} / \mathrm{Mg}$ is about $0.049 / 0.047 / 0.059 \AA$, indicating the high stability of AsP as anode compared to the black phosphorene with a structural distortion of $0.11 \AA^{63}$ In addition, the variation in the total energy of $(\mathrm{Na} / \mathrm{K} / \mathrm{Mg}) @ A s P$ systems versus the perpendicular distance separating single $\mathrm{Na} / \mathrm{K} / \mathrm{Mg}$ atom to the $\alpha$-AsP surface is examined to get insight into the vertical distance at which the system behaves like isolated without any interaction 

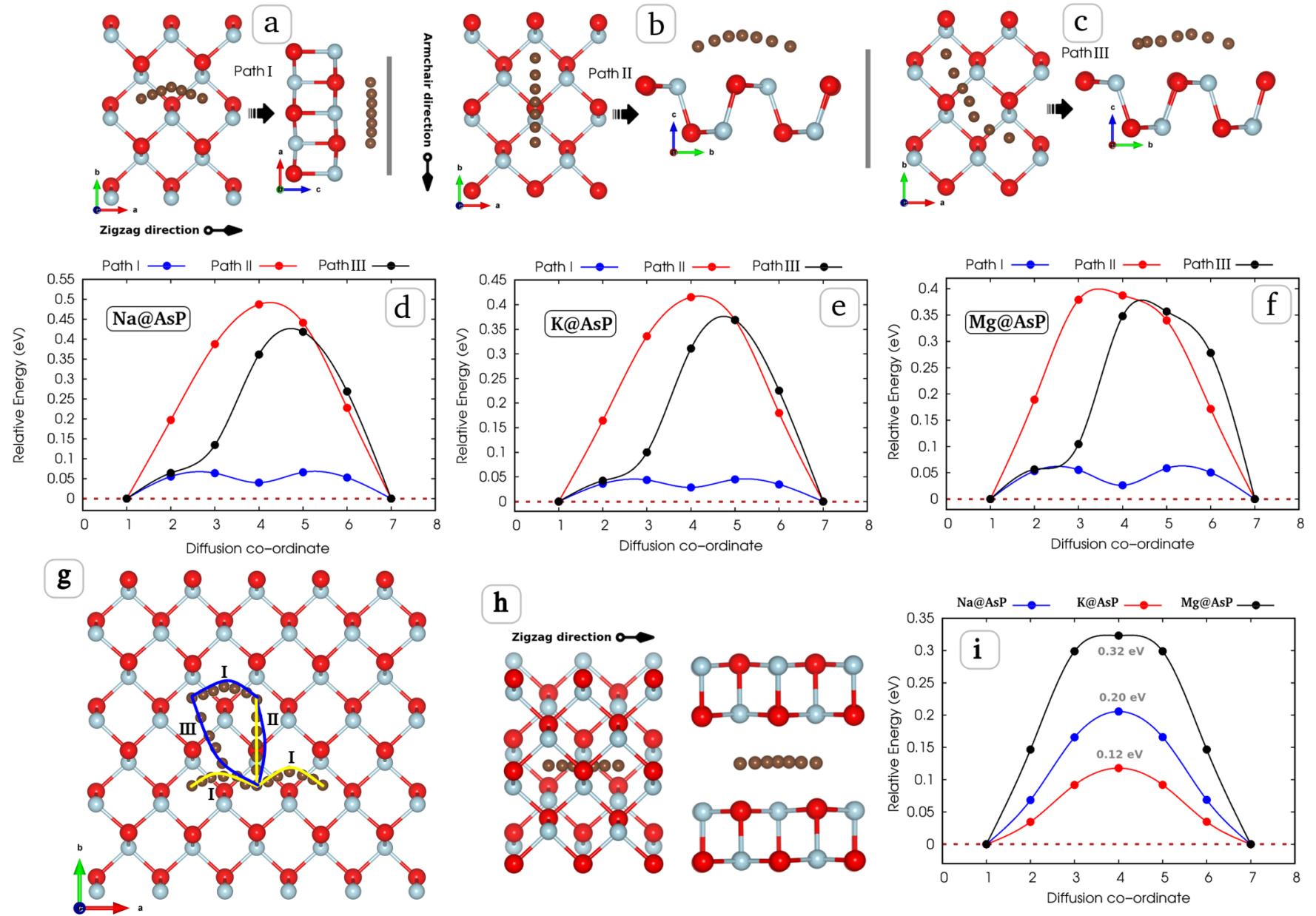

Figure 5. $(\mathrm{a}-\mathrm{c})$ Schematic view showing the single $(\mathrm{Na} / \mathrm{K} / \mathrm{Mg})$-atom diffusion pathways on the surface of $\alpha$-AsP with the corresponding minimum-energy path (MEP), (d) for Na atom, (e) K atom, and (f) Mg atom diffusing along three different pathways on $\alpha$-AsP. (g) Schematic view of the two possible percolating paths (shown by blue and yellow lines) where the net migration barrier leads by path II. (h) Top and side snapshots of the diffusion path of single $(\mathrm{Na} / \mathrm{K} / \mathrm{Mg})$-atom in bulk AsP along the zigzag directions. (i) Corresponding minimum-energy path (MEP) of single $(\mathrm{Na} / \mathrm{K} / \mathrm{Mg})$ atom diffusing along path $\mathrm{I}$ in bulk AsP.

between the alkali metal and the surface, as illustrated in Figure 3. It can be clearly seen that the variation of relative energy for $h_{(\mathrm{Na} / \mathrm{K} / \mathrm{Mg})-\mathrm{AsP}}>7 \AA$ is insignificant owing to the noninteraction between the $(\mathrm{Na} / \mathrm{K} / \mathrm{Mg})$ atoms and the $\alpha$-AsP sheet. Additionally, there is a noticeable relative energy change of less than $\sim 1.5 \mathrm{eV}$ in the case of $\mathrm{Na} / \mathrm{K}$ atom with a vertical distance of 1.996/2.441 $\AA$ and about $\sim 0.9 \mathrm{eV}$ with an equilibrium distance of $1.962 \AA$, and in the case of $\mathrm{Mg}$ atom, also the vertical distance of $10 \AA$ provides a clear description of the strong interaction of $\mathrm{Na} / \mathrm{K} / \mathrm{Mg}$ atoms and the AsP surface. It can be deduced from Figure 3: (i) the interaction between $\mathrm{Na} / \mathrm{K} / \mathrm{Mg}$ atoms and the AsP monolayer is mostly driven by the Coulomb interaction, (ii) the van der Waals interaction contribution can be overlooked, and (iii) there is no energy barrier between the $\mathrm{Na} / \mathrm{K} / \mathrm{Mg}$ and AsP monolayer.

A more detailed understanding of the binding process can be further examined through the charge density difference of single $(\mathrm{Na} / \mathrm{K} / \mathrm{M})$ atom adsorbed at the most favorable site on the $\alpha$-AsP monolayer by means of the equation given below

$$
\Delta \rho=\rho_{(\mathrm{Na} / \mathrm{K} / \mathrm{Mg}) @ \mathrm{AsP}}-\rho_{\mathrm{AsP}}-\rho_{\mathrm{Na} / \mathrm{K} / \mathrm{Mg}}
$$

wherein $\rho_{\text {AsP }}$ and $\rho_{(\mathrm{Na} / \mathrm{K} / \mathrm{Mg}) @ \mathrm{AsP}}$ are the electron charge densities of the $\alpha$-AsP system before and after the adsorption of single $(\mathrm{Na} / \mathrm{K} / \mathrm{M})$ atom, respectively, and $\rho_{\mathrm{Na} / \mathrm{K} / \mathrm{Mg}}$ represents the electron charge density of single $(\mathrm{Na} / \mathrm{K} / \mathrm{M})$ atom isolated in the system by keeping the same lattice parameters without any further optimization. Figure 4 depicts the depletion and accumulation of charges for the three systems represented as isosurface distributed charge density plots. One can notice that the charge-accumulating zone represented by the yellow color is situated within the $(\mathrm{Na} / \mathrm{K} /$ $\mathrm{M})$ atom and the surface of our material, and the depletion of charge represented by the green color surrounds the $(\mathrm{Na} / \mathrm{K} /$ M) atom, which indicates that the alkali metal considered donated charge to the AsP surface, which results in the higher electronegativity of As and $\mathrm{P}$ atoms compared to that of $(\mathrm{Na} /$ $\mathrm{K} / \mathrm{M}$ ) atoms. Moreover, the charge transfer approach performed using Bader charge algorithm and the results are summarized in Table 1 . It can be noticed that each single $\mathrm{Na}$, $\mathrm{K}$, and $\mathrm{Mg}$ loses an average electron charge of about 0.782 , 0.816 , and $0.870 \mathrm{lel}$, respectively.

2.3. Diffusion Kinetics of $(\mathrm{Na} / \mathrm{K} / \mathrm{Mg})$ Atom on the $\alpha$ AsP Surface. High-efficiency battery development is a critically dependent capability of the anode materials especially on the charging and discharging process, which is largely driven by the kinetic properties of electron transfer and ionic mobility. Accordingly, the electronic behavior of single $(\mathrm{Na} /$ $\mathrm{K} / \mathrm{Mg}$ ) adsorbed on the $\alpha$-AsP system is investigated by 
Table 2. Comparative Summary of Specific Capacities, Diffusion Barriers, and Open-Circuit Voltages of Different Anode Materials for NIBs/KIBs/MIBs Available from the Literature

\begin{tabular}{|c|c|c|c|c|c|c|c|c|c|}
\hline \multirow[b]{2}{*}{$\alpha$-phase $2 \mathrm{D}$ materials } & \multicolumn{3}{|c|}{ specific capacity $(\mathrm{mAh} / \mathrm{g})$} & \multicolumn{3}{|c|}{ diffusion barrier $(\mathrm{eV})$} & \multicolumn{3}{|c|}{ open-circuit voltage (V) } \\
\hline & $\mathrm{Na}$ & $\mathrm{K}$ & $\mathrm{Mg}$ & $\mathrm{Na}$ & $\mathrm{K}$ & $\mathrm{Mg}$ & $\mathrm{Na}$ & $\mathrm{K}$ & $\mathrm{Mg}$ \\
\hline$\alpha$-AsP & 759.24 & 506.16 & 253.08 & 0.06 & 0.04 & 0.05 & 0.84 & 0.93 & 0.52 \\
\hline$\alpha-\mathrm{P}^{a}$ & $433-865$ & & & 0.04 & & & & & 0.89 \\
\hline$\alpha-\mathrm{GeS}^{b}$ & 512.0 & 256.0 & & 0.09 & 0.05 & & 0.23 & 0.36 & \\
\hline$\alpha-\mathrm{GeSe}^{c}$ & 707.0 & 530.0 & & 0.115 & 0.11 & & 0.27 & 0.38 & \\
\hline$\alpha-\mathrm{SiS}^{d}$ & 445.6 & & & 0.135 & & & 0.2 & & \\
\hline$\alpha-\mathrm{SiSe}^{d}$ & 250.3 & & & 0.158 & & & 0.2 & & \\
\hline
\end{tabular}

${ }^{a}$ Refs $63,65 .{ }^{b} \operatorname{Ref} 60 .{ }^{c} \operatorname{Ref} 61 .{ }^{d}$ Ref 59.

computing the electronic band structure with the corresponding total density of state and depicted in Figure S1, SI. Our findings clearly indicate that all our anode material changes the electronic characteristic from a semiconductor to a metallic characteristic after a single $(\mathrm{Na} / \mathrm{K} / \mathrm{Mg})$ adsorption, ensuring the rapid and fast transfer of electrons in the anode throughout the full adsorption and desorption reaction, which plays a key role in the high-throughput capacity of post-Li-ion batteries.

Furthermore, the dilute $(\mathrm{Na} / \mathrm{K} / \mathrm{Mg})$ diffusion paths with their corresponding minimum-energy profile (MEP) were explored by the CI-NEB method for one $(\mathrm{Na} / \mathrm{K} / \mathrm{Mg})$ atom scattered on the surface of the $\alpha$-AsP monolayer. Figure 5a-f illustrates the top and side views of the schematic illustration of three scattering paths considered in our study and their corresponding relative energy profile. The three chosen paths consist of a symmetrical $(\mathrm{Na} / \mathrm{K} / \mathrm{Mg})$ diffusion along the zigzag ( $a$-direction) and armchair ( $b$-direction) channels and over the $\left(\mathrm{H}_{2}\right)$ of the $\alpha$-AsP surface. Path I implies that the $(\mathrm{Na} / \mathrm{K} / \mathrm{Mg})$ ion diffuses from the most stable site characterized by the highest binding strength $\left(\mathrm{H}_{1}\right)$ to the closest $\left(\mathrm{H}_{1}\right)$ site along the zigzag direction, and it can be clearly noticed that the $(\mathrm{Na} / \mathrm{K} /$ $\mathrm{Mg}$ ) atom needs to exceed a MEP of about $0.062,0.043$, and $0.054 \mathrm{eV}$, respectively, to diffuse toward the closest $\left(\mathrm{H}_{1}\right)$ site. For path II, the $(\mathrm{Na} / \mathrm{K} / \mathrm{Mg})$ atom diffuses along the armchair channel with computed MEPs of approximately 0.489, 0.414, and $0.383 \mathrm{eV}$, respectively. In the case of path III, the $(\mathrm{Na} / \mathrm{K} /$ $\mathrm{Mg}$ ) atom migrates over the $\left(\mathrm{H}_{2}\right)$ site with calculated minimum barrier profiles of $0.412,0.362$, and $0.405 \mathrm{eV}$, respectively. These obtained values of diffusion barrier are in line with the results of binding strength presented in Table 1; the $(\mathrm{Na} / \mathrm{K} / \mathrm{Mg})$-ion migration barrier in the first pathway exhibits the lowest energy barrier compared to other pathways. It can be noticed that the diffusion barrier profile progressively decreases with respect to the increase in the atomic number of $\mathrm{Na}$ (11), K (19), and $\mathrm{Mg}$ (12). For comparison purposes, our computed diffusion barriers of $(\mathrm{Na} / \mathrm{K} / \mathrm{Mg})$ atoms along the first pathway on the $\alpha$-AsP surface are similar and substantially lower compared to those revealed in earlier identified potential 2D $\alpha$-phase anode materials, such as the most studied black phosphorene with a minimum diffusion barrier of about 0.04 $\mathrm{eV}$ in the case of $\mathrm{Na}$ atom, ${ }^{43} \alpha-\mathrm{GeS}$ monolayer with an energy barrier of $0.09 / 0.05 \mathrm{eV}$ for $\mathrm{Na} / \mathrm{K},{ }^{60}$ and $\alpha$-GeSe monolayer with a minimum-energy profile of $0.115 / 0.11 \mathrm{eV}$ in the case of $\mathrm{Na} / \mathrm{K}$ atom, ${ }^{61}$ as summarized in Table 2 . It shows that $\mathrm{Na} / \mathrm{K} /$ $\mathrm{Mg}$ atoms are able to diffuse more quickly along the first pathway over AsP compared to other paths, and therefore, a high charge/discharge efficiency is expected. To summarize, we have investigated three migration barriers and found that path I exhibits the lowest energy barrier. If we consider only this pathway (i.e., path $\mathrm{I}$ ), the $\mathrm{Na} / \mathrm{K} / \mathrm{Mg}$ atom will migrate in one crystallographic direction, i.e., $a$-axis only, and by moving along the $a$-axis, it will never reach other crystallographic directions, i.e., $b$ - and $c$-axes. From the practical point of view, accessing the possible binding sites for alkali atoms along the $b$ and $c$ axes or connecting those sites with the sites along the $a$ axis could be essential to enhance the performance of the anodes. All of these sites could be connected by overcoming the net migration barrier, which is lead by path II, having the highest energy barrier out of the three considered possible pathways. In this case, we will have two distinct percolating pathways: (1) either the $\mathrm{Na} / \mathrm{K} / \mathrm{Mg}$ atoms could migrate along the $b$-axis (by overcoming the barrier of path II), then along the $a$-axis (i.e., this direction combines path II and path I) (yellow line in Figure 5g) or (2) after overcoming the barrier along the $b$-axis, atoms could migrate along path III, then along path $I$ to return to its initial start position (blue line in Figure $5 \mathrm{~g}$ ). For further migration analysis in this study, although we have considered only path I, we think a similar picture of the net migration as discussed above will be applicable for other studied systems in this study.

In addition, the dilute $(\mathrm{Na} / \mathrm{K} / \mathrm{Mg})$ diffusion along the zigzag direction (path $\mathrm{I}$ ), which exhibits the lowest energy barrier, was explored in the case of the AsP bulk system. The top and side views of the schematic representation of the pathway considered with the corresponding MEP are illustrated in Figure 5h,i. Our results show that in the case of $(\mathrm{Na} / \mathrm{K} / \mathrm{Mg})$ atom, only one peak is obtained with minimum barrier profiles of about $0.20,0.12$, and $0.32 \mathrm{eV}$, respectively. These values are lower than those obtained in the case of bulk $\mathrm{GeS}$ and GSNS material; the MEP of $\mathrm{K}$ is lower compared to those of $\mathrm{Na}$ and $\mathrm{Mg}$, which can be attributed to great atomic radius of $\mathrm{K}$ compared to $\mathrm{Na}$ and $\mathrm{Mg}$ and then to the strong interaction existing between the $\mathrm{K}$ and AsP monolayer rather than that of the $\mathrm{Na} / \mathrm{Mg}$ and AsP monolayers. According to an in-depth analysis of these values, one can affirm that our suggested bulk and monolayer $\alpha$-AsP anode material offers a fast and effective $(\mathrm{Na} / \mathrm{K} / \mathrm{Mg})$ diffusion and fast chargedischarge rates. More convincing statement can be made if we compare these diffusion barrier values to other attractive $\alpha$ phase anode materials, which have been proposed previously and are listed in Table 1.

2.4. Equilibrium Voltage and Theoretical Capacity. Additionally, to understand the electrochemical potentials of the anode, we have computed the equilibrium potential and the theoretical specific capacity of the $\alpha$-AsP monolayer as an anode material in a post-Li-ion battery. With the purpose of highlighting the intercalation process, $\mathrm{Na} / \mathrm{K} / \mathrm{Mg}$ ions were gradually inserted on both sides of the $\alpha$-AsP monolayer. For each $\mathrm{Na} / \mathrm{K} / \mathrm{Mg}$ concentration, we have employed the basinhopping Monte Carlo algorithm (BHMC) ${ }^{64}$ to achieve overall 

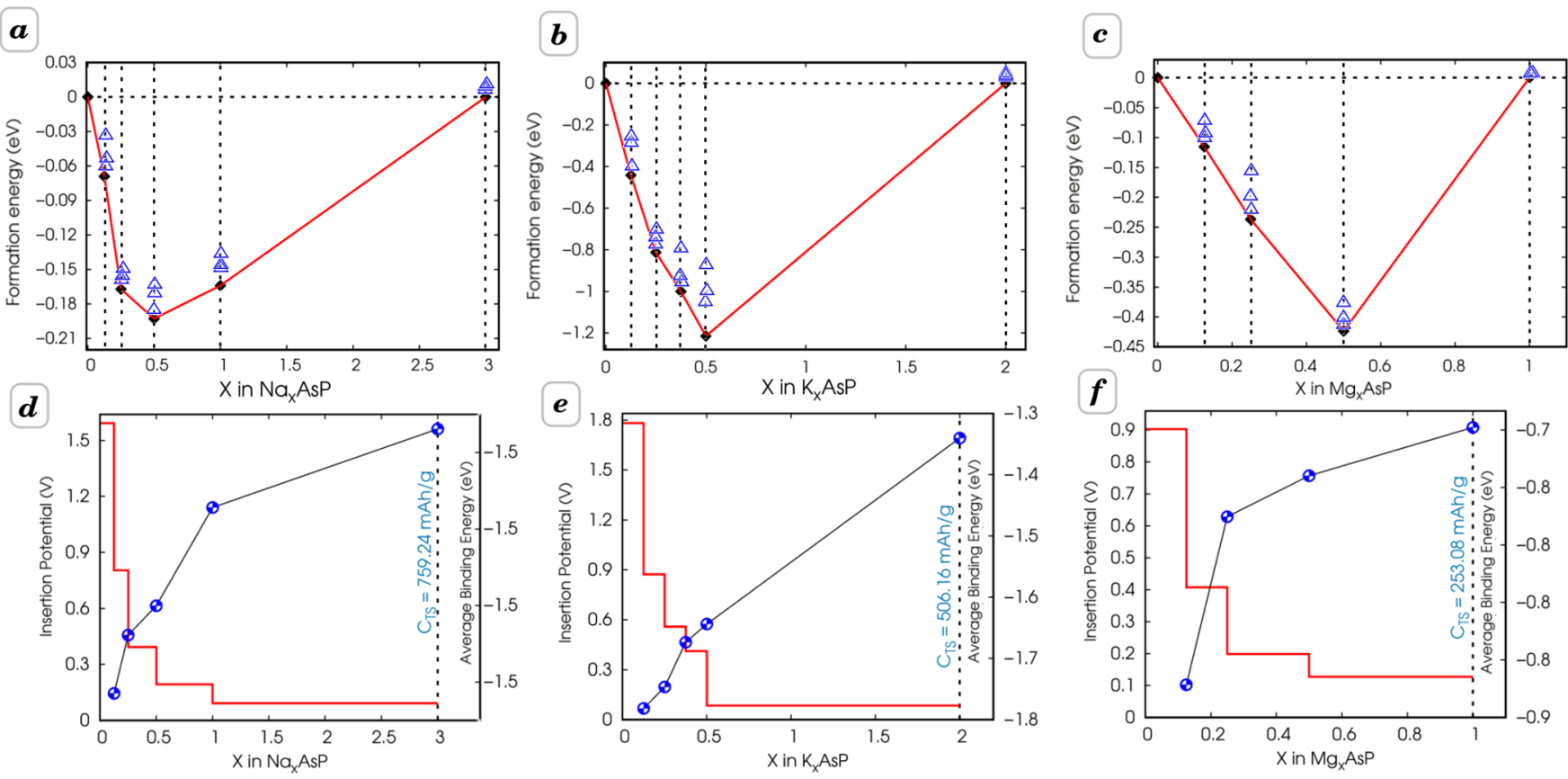

Figure 6. $(\mathrm{a}-\mathrm{c})$ Formation energies considering the ground-state structures found by adding atom by atom to the host structure for $\mathrm{Na}_{x} \mathrm{AsP}_{\mathrm{P}}$, $\mathrm{K}_{x} \mathrm{AsP}$, and $\mathrm{Mg}_{x} \mathrm{AsP}$ systems, respectively. ( $\mathrm{d}-\mathrm{f}$ ) Open-circuit voltage as a function of concentration $x$ (in eV) for $\mathrm{Na}_{3} \mathrm{AsP}, \mathrm{K}_{2} \mathrm{AsP}$, and $\mathrm{MgAsP}$, respectively.

minimum structures. With the aim of getting the lowest energetic setup available, a total of 100 starting structures were examined where the $\mathrm{Na} / \mathrm{K} / \mathrm{Mg}$ ions are allowed to choose the binding positions on both sides of the pristine surface and the lowest-energy configuration is adopted to be fully optimized under energy and force convergence criteria. A $2 \times 2 \times 1$ supercell was assumed where the concentrations vary from 1 to 24 in the case of $\mathrm{Na}$ atom, from 1 to 16 for $\mathrm{K}$ atom, and from 1 to 8 for $\mathrm{Mg}$ atom. At this point, to evaluate the estimated open-circuit voltage, the half-cell reaction is taken as follows

$$
\left(n_{2}-n_{1}\right) \mathrm{M}+n_{2}-n_{1} \mathrm{e}^{-}+\mathrm{M}_{n_{1}} \mathrm{AsP} \rightleftharpoons \mathrm{M}_{n_{2}} \mathrm{AsP}
$$

where $\mathrm{M}$ indicates $\mathrm{Na}^{+} / \mathrm{K}^{+} / \mathrm{Mg}^{2+}$, and $n_{1}$ and $n_{2}$ represent the respective concentrations of $\mathrm{Na}^{+} / \mathrm{K}^{+} / \mathrm{Mg}^{2+}$ absorbed on the $\alpha$-AsP monolayer. For every given concentration, we carried out a BHMC, and then only the global minimum structure with the lowest energy was used in the further calculations. The highest concentration has been determined according to two relevant principles: first, the average binding strength, which requires negative values, and the second concerns the thermal stability of the electrode during the charge/discharge process. It is important to point out that for the second requirement, the $\alpha$-AsP anode recovery process with completely removed $\mathrm{Na}^{+} / \mathrm{K}^{+} / \mathrm{Mg}^{2+}$ through AIMD simulations was carried out at $300 \mathrm{~K}$ and a time scale of 10 ps, and the final anodes structures are illustrated in Figure S2 (SI). Subsequently, the resulting structures were taken, and a further AIMD simulation with 5 and 10 ps as well as an energy optimization computation was then conducted, which provided the starting $\alpha$-AsP structure, which proves the reversible characteristic of the $\alpha$-AsP anode material. The structural parameters are found to be in good accordance with our pristine structure. Furthermore, it can be noticed that there were no significant deformation or bond breakage in the 2D $\alpha$ AsP anode through $\left(\mathrm{Na}^{+} / \mathrm{K}^{+} / \mathrm{Mg}^{2+}\right)$ intercalation, except slight thermal vibrations of As and $\mathrm{P}$ atoms have been noticed in the case of $\mathrm{Mg}^{2+}$ intercalation.

We further checked the stability of every single concentration through the average adsorption energy and of the intermediate phases relative to ultimate final structures (the full concentrations) by means of respective formulas

$$
\begin{aligned}
& E_{\text {avg }}=\frac{E_{(\mathrm{Na} / \mathrm{K} / \mathrm{Mg})_{n} @ \mathrm{AsP}}-E_{\mathrm{AsP}}-\left(n E_{\mathrm{Na} / \mathrm{K} / \mathrm{Mg}}\right)}{n} \\
& E_{\mathrm{f}}=E_{(\mathrm{Na} / \mathrm{K} / \mathrm{Mg})_{n} @ \mathrm{AsP}}-\left[\frac{n \cdot E_{\mathrm{Na}_{3} / \mathrm{K}_{2} / \mathrm{Mg} @ \mathrm{AsP}+\left(x_{\max }-n\right) E_{\mathrm{AsP}}}}{x_{\max }}\right]
\end{aligned}
$$

where $E$ corresponds to the total energy of each underlying material and $x_{\max }$ refers to the high $\left(\mathrm{Na}^{+} / \mathrm{K}^{+} / \mathrm{Mg}^{2+}\right)$ concentrations. Accordingly, the intercalation potential is derived based on the phases arising in the convex hull tie line. Consequently, the voltage profile is determined through the mean of the voltages across the segments of different configurations and calculated as follows

$$
\begin{aligned}
& V= \\
& \frac{E_{(\mathrm{Na} / \mathrm{K} / \mathrm{Mg})_{n_{1}} \mathrm{AsP}}-E_{(\mathrm{Na} / \mathrm{K} / \mathrm{Mg})_{n_{2}} \mathrm{AsP}}+\left(n_{2}-n_{1}\right) E_{\mathrm{Na} / \mathrm{K} / \mathrm{Mg}}}{\left(n_{2}-n_{1}\right) e}
\end{aligned}
$$

where $E_{(\mathrm{Na} / \mathrm{K} / \mathrm{Mg})_{n 1 / 2} \mathrm{AsP}}$ refers to the energy of $(\mathrm{Na} / \mathrm{K} /$ $\mathrm{Mg})_{n_{1 / 2}}$ AsP. Figure $6 \mathrm{a}-\mathrm{c}$ illustrates the formation energies of $(\mathrm{Na} / \mathrm{K} / \mathrm{Mg})_{x} \mathrm{AsP}$ systems, and the intermediate stable phases with the lowest formation energies situated on the hull are indicated by a black circle. These intermediate stable configurations are subsequently used to compute the opencircuit potential as outlined in eq 7 . One should notice that the $\mathrm{Na}^{+} / \mathrm{K}^{+} / \mathrm{Mg}^{2+}$ intercalation process is expected to yield varying potential profiles owing to different stable intermediate 

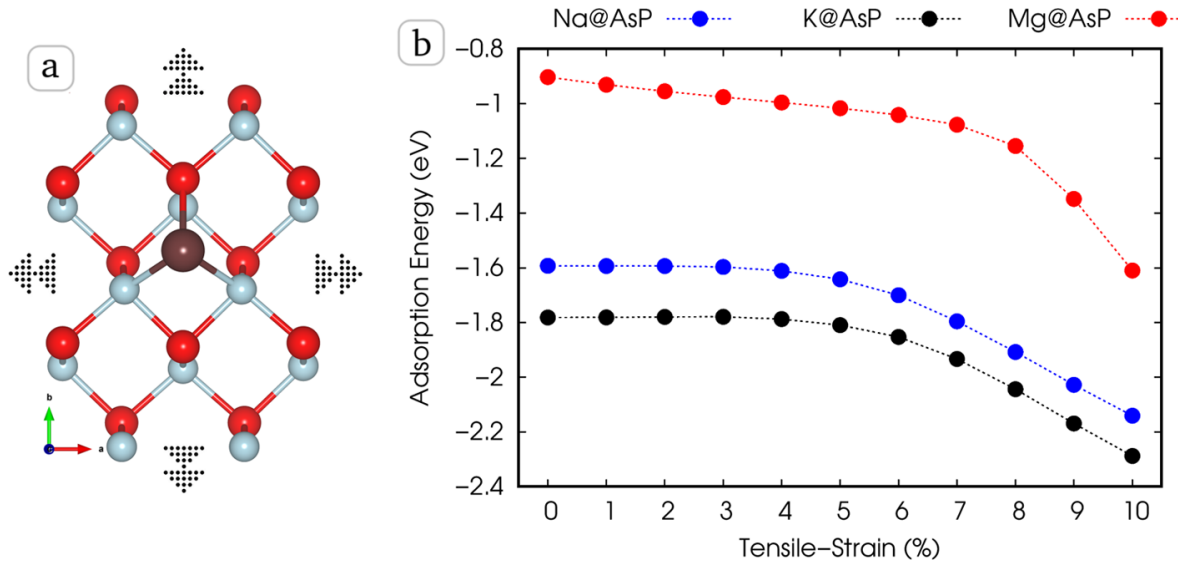

Figure 7. (a) Schematic illustration of the $\alpha$-AsP monolayer by adjusting Biaxial tensile strain optimization to single $(\mathrm{Na} / \mathrm{K} / \mathrm{Mg})$ atom adsorbed on the $\alpha$-AsP monolayer. (b) Variation of adsorption energy of single $(\mathrm{Na} / \mathrm{K} / \mathrm{Mg})$ atom on $\alpha$-AsP with respect to tensile strain.
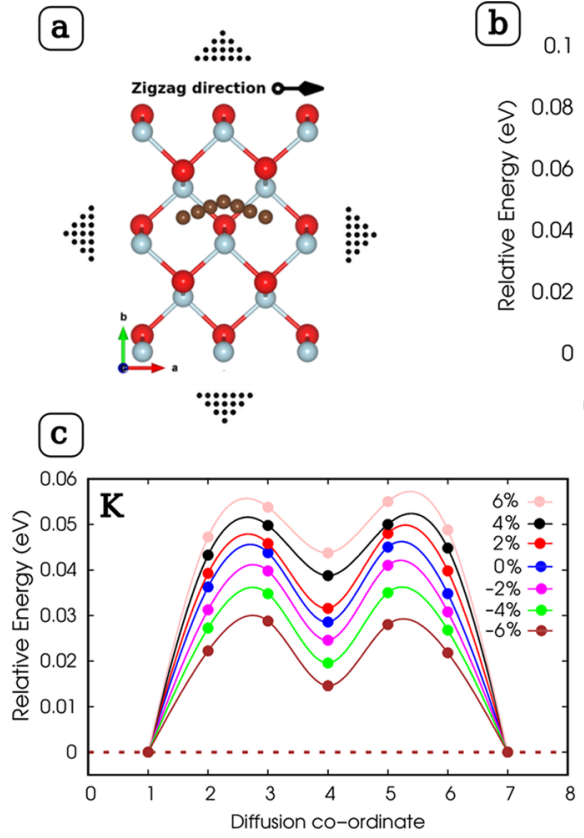

(b)

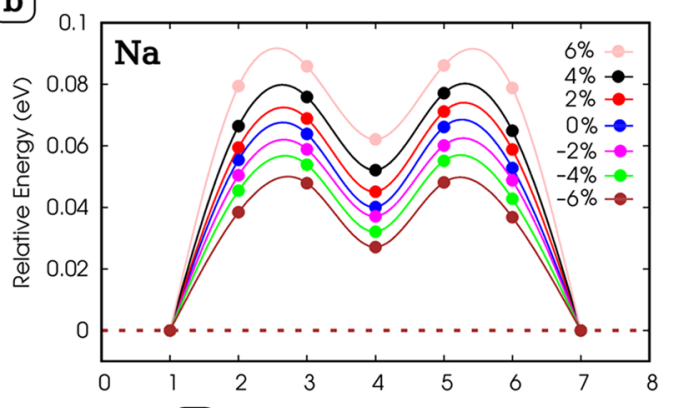

d

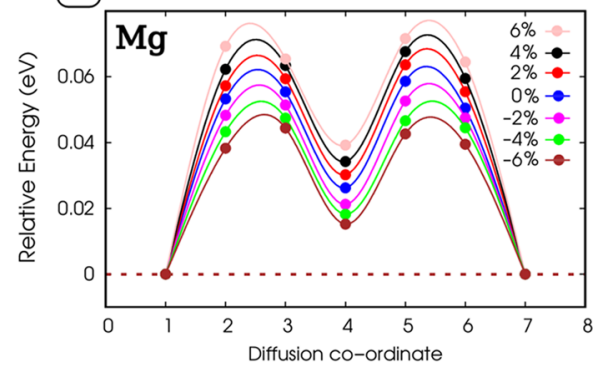

Figure 8. (a) Schematic view of single $(\mathrm{Na} / \mathrm{K} / \mathrm{Mg})$ atom diffusing along the first path in $\alpha$-AsP under biaxial strain. (b-d) Minimum-energy path (MEP) with respect to biaxial strain (compressive and tensile strain) for $\mathrm{Na}, \mathrm{K}$, and $\mathrm{K}$ atoms, respectively.

configurations obtained. Figure $6 \mathrm{~d}-\mathrm{f}$ illustrates the opencircuit voltage with the corresponding average binding energies. It can be clearly seen that five discharge profile plateaus are obtained in the case of $\mathrm{Na} / \mathrm{K}$ with an average open-circuit voltage of about $0.84 / 0.93 \mathrm{~V}$ and four insertion potential plateaus in the case of $\mathrm{Mg}$ with an average $\mathrm{OCV}$ of $0.52 \mathrm{~V}$. Additionally, over other $\alpha$-phase 2D materials as outlined in Table 2, $\alpha$-AsP offers a more promising potential for developing a high-voltage rechargeable post-Li-ion battery.

In addition, the theoretical specific capacity of the AsP monolayer for $\left(\mathrm{Na}^{+} / \mathrm{K}^{+} / \mathrm{Mg}^{2+}\right)$ storage is estimated based on the following formula

$$
C=\frac{x_{\max } z \cdot F \cdot 10^{3}}{W_{\mathrm{AsP}}}
$$

where $x_{\max } z$, and $F$ refer to the high $\left(\mathrm{Na}^{+} / \mathrm{K}^{+} / \mathrm{Mg}^{+2}\right)$ concentrations obtained in the convex hull, the valence state of completely ionized $(\mathrm{Na} / \mathrm{K} / \mathrm{Mg})$, and the Faraday constant, respectively, and $W_{\mathrm{AsP}}$ denotes the molecular weight of the $2 \mathrm{D}$
AsP monolayer. From this, the computed theoretical specific $\left(\mathrm{Na}^{+} / \mathrm{K}^{+} / \mathrm{Mg}^{+2}\right)$ capacities are $759.24,506.16$, and 253.08 $\mathrm{mAh} / \mathrm{g}$, respectively. Such values are considerably greater than that of the commercially available graphite and of other $\alpha$ phase 2D materials such as $\alpha-\mathrm{GeS}^{60}$ and $\alpha-\mathrm{GeSe}^{61}$ for both $\mathrm{Na} / \mathrm{K}$, as summarized in Table 2 .

2.5. Effect of Biaxial Strain Engineering. Furthermore, we have applied tensile strain in the $\alpha$-AsP monolayer, which varies from -10 to $10 \%$ with the interval of $1 \%$. First, we will discuss the electronic properties and then study its effects on $\mathrm{Na} / \mathrm{K} / \mathrm{Mg}$-ion adsorption and migrations of $\mathrm{Na} / \mathrm{K} / \mathrm{Mg}$ ions on the $\alpha$-AsP monolayer surfaces. The applied strain is defined as

$$
\epsilon=\left(a-a_{0}\right) / a_{0}
$$

where $a$ and $a_{0}$ represent the lattice constant of the $\alpha$-AsP monolayer with strain and without strain, respectively. To study the effect of strain on the electronic properties and understand the physical/chemical origin of the enhanced adsorption, we have plotted the electronic band gaps as a 
function of applied strain. Figure S3 shows the effect of strain (compressive and tensile) on electronic band gap. It was clearly seen that the applied strain significantly changes the electronic properties of the $\alpha$-AsP monolayer. At the compressive strain, the band gap reduces linearly with increasing strain, and after $-10 \%$ strain, it shows metallic behaviors using the HSE06 functional. The tensile strain displayed an increasing band gap with increasing strain, and after a certain strain (i.e., 5\%), it started decreasing band gap. We can see that the band gap at a higher strain of $10 \%$ shows almost the same band gap without strain. The modification of electronic properties with applying strain will be beneficial for adsorption of metal ions and other properties.

Figure 7 displays the effect of tensile strain for the calculated adsorption difference and adsorption energy versus strain. Remarkably, we can see that the minimal adatoms to As/P bonding distances maintain (i.e., very small variation in a distance of 0.01-0.04 $\AA$ from As atom while 0.01-0.12 $\AA$ from $\mathrm{P}$ atom from initial distances) with increasing strain for $\mathrm{Na} / \mathrm{K} /$ Mg-ion adsorption as shown in Table S2. This is accompanied by a significant increase in energy adsorption. The significant variation of structural distortion (i.e., buckling height between As and $\mathrm{P}$ layers) was also seen. In addition, the adsorption of these $\mathrm{Na} / \mathrm{K} / \mathrm{Mg}$ ions on the surface of the $\alpha$-AsP monolayer is shown in Figure $7 \mathrm{a}$. The adsorption energy of $\mathrm{Na} / \mathrm{K} / \mathrm{Mg}$ ions gradually increases from without strain to applied tensile strain $10 \%$. The adsorption energy for $\mathrm{Mg}$ ions increases 2 times from without strain, while 1.3 times increases in the case of $\mathrm{Na} / \mathrm{K}$ ions (see Figure $7 \mathrm{~b}$ ). It means that the applied strain is an effective approach to significantly enhance the adsorption energy of these metal ions.

Furthermore, to demonstrate the relationship between migration of metal ions $(\mathrm{Na} / \mathrm{K} / \mathrm{Mg}$-ions) and applied strain to see the energy barriers. During the applied strain, we have displayed only first path for the minimum-energy path (MEP) of a single $\mathrm{Na} / \mathrm{K} / \mathrm{Mg}$ atom as presented in Figure $8 \mathrm{a}$. The migrations of these considered ions were subjected to biaxial compressive and tensile strain from -6 to $+6 \%$. From Figure $8 \mathrm{~b}-\mathrm{d}$, we can see that the migration of energy barriers for $\mathrm{Na}$ / $\mathrm{K} / \mathrm{Mg}$ ions displayed a similar pathway. We can also see that the $\mathrm{Mg}$ has a much smaller energy barrier, which suggests a faster diffusion process compared to the other two $\mathrm{Na}$ and $\mathrm{K}$ ions. It can be seen that the $\mathrm{K}$ ions are more sensitive to compressive strain because they have a very low energy barrier. It means that the diffusion process of $\mathrm{K}$ ions is much faster at compressive strain. Also, the tensile strain increases the migration energy barrier while compressive strain decreases the energy barrier. From these results, we can say that the compressive strain will be a more effective approach to enhance the migration of these metal ions for battery applications.

\section{CONCLUSIONS}

Basically, we have investigated the prospective applicability of using the $\alpha$-phase arsenic phosphorus monolayer $(\alpha$-AsP) as an electrode material for $\left(\mathrm{Na}^{+}, \mathrm{K}^{+}, \mathrm{Mg}^{2+}\right)$-based rechargeable batteries. Through DFT-based calculations and AIMD simulations, both the thermodynamics and kinetics of $\left(\mathrm{Na}^{+}\right.$, $\mathrm{K}^{+}, \mathrm{Mg}^{2+}$ ) intercalation were thoroughly evaluated. Our findings show that the $\alpha$-AsP monolayer as an electrode presents a high affinity toward $\mathrm{Na}, \mathrm{K}$, and $\mathrm{Mg}$ atoms with negative binding strengths of about $-1.59,-1.78$, and -0.91 , respectively. Additionally, it is determined that the $\left(\mathrm{Na}^{+}, \mathrm{K}^{+}\right.$,
$\mathrm{Mg}^{2+}$ ) storage on both sides of the $\alpha$-AsP surface can reach very high theoretical specific capacities of about $759.24 \mathrm{mAh} / \mathrm{g}$ $(\mathrm{Na}), 506.16 \mathrm{mAh} / \mathrm{g}(\mathrm{K})$, and $253.08 \mathrm{mAh} / \mathrm{g}(\mathrm{Mg})$ greater relative to standard commercial graphite anode and significantly greater relative to many other $\alpha$-phase $2 \mathrm{D}$ materials identified to date. The stability and reversibility in geometrical structure change during the $\left(\mathrm{Na}^{+}, \mathrm{K}^{+}, \mathrm{Mg}^{2+}\right)$ insertion were also checked through the AIMD simulations. Based on our findings, the new and recently synthesized 2D $\alpha$-phase arsenic phosphorus monolayer is worthy of serious consideration by the energy storage research and industry community. Its suitability as a $2 \mathrm{D}$ material of basic applications is also convincing.

\section{ASSOCIATED CONTENT}

\section{Supporting Information}

The Supporting Information is available free of charge at https://pubs.acs.org/doi/10.1021/acsaem.1c01247.

Computational frameworks, structural and electronic parameters of 2D black AsP material, electronic properties of single $(\mathrm{Na} / \mathrm{K} / \mathrm{Mg})$ atom adsorbed on the $\alpha$-AsP monolayer, $\alpha$-AsP anode recovery process (AIMD), electronic band gap as a function of biaxial strain using GGA-PBE and HSE06 functional, and the structural parameters of the $\mathrm{Na} / \mathrm{K} / \mathrm{Mg}$ atom adsorbed on the AsP monolayer as a function of biaxial strain (PDF)

\section{AUTHOR INFORMATION}

\section{Corresponding Author}

Rajeev Ahuja - Condensed Matter Theory Group, Materials Theory Division, Department of Physics and Astronomy, Uppsala University, 75120 Uppsala, Sweden; Applied Materials Physics, Department of Materials and Engineering, Royal Institute of Technology (KTH), S-100 44 Stockholm, Sweden; orcid.org/0000-0003-1231-9994; Email: rajeev.ahuja@physics.uu.se

\section{Authors}

Nabil Khossossi - Condensed Matter Theory Group, Materials Theory Division, Department of Physics and Astronomy, Uppsala University, 75120 Uppsala, Sweden; Laboratoire de Physique des Matériaux et Modélisations des Systèmes, (LP2MS), Unité Associée au CNRST-URAC 08, Faculty of Sciences, Department of Physics, Moulay Ismail

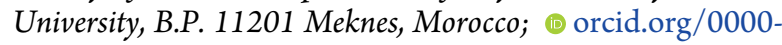
0002-3914-4162

Deobrat Singh - Condensed Matter Theory Group, Materials Theory Division, Department of Physics and Astronomy, Uppsala University, 75120 Uppsala, Sweden; 이이.org/ 0000-0001-7246-8743

Amitava Banerjee - Condensed Matter Theory Group, Materials Theory Division, Department of Physics and Astronomy, Uppsala University, 75120 Uppsala, Sweden

Wei Luo - Condensed Matter Theory Group, Materials Theory Division, Department of Physics and Astronomy, Uppsala University, 75120 Uppsala, Sweden

Ismail Essaoudi - Laboratoire de Physique des Matériaux et Modélisations des Systèmes, (LP2MS), Unité Associée au CNRST-URAC 08, Faculty of Sciences, Department of Physics, Moulay Ismail University, B.P. 11201 Meknes, Morocco 
Abdelmajid Ainane - Condensed Matter Theory Group, Materials Theory Division, Department of Physics and Astronomy, Uppsala University, 75120 Uppsala, Sweden; Laboratoire de Physique des Matériaux et Modélisations des Systèmes, (LP2MS), Unité Associée au CNRST-URAC 08, Faculty of Sciences, Department of Physics, Moulay Ismail University, B.P. 11201 Meknes, Morocco; Max-PlanckInstitut für Physik Complexer Systeme, D-01187 Dresden, Germany

Complete contact information is available at:

https://pubs.acs.org/10.1021/acsaem.1c01247

\section{Notes}

The authors declare no competing financial interest.

\section{ACKNOWLEDGMENTS}

N.K., D.S., and R.A. gratefully acknowledge computational resources from the Swedish National Infrastructure for Computing SNIC (2019/1-25 \& 2020/1-40) and HPC2N. N.K., D.S., W.L., and R.A. acknowledge support from Swedish Research Council (VR-2016-06014 \& VR-2020-04410). A.A. and I.E. acknowledge the PPR2 project: (MISTERSFCCNRST).

\section{REFERENCES}

(1) Su, F.; Hou, X.; Qin, J.; Wu, Z.-S. Recent Advances and Challenges of Two-Dimensional Materials for High-Energy and HighPower Lithium-Ion Capacitors. Batteries Supercaps 2020, 3, 10-29.

(2) Lukatskaya, M. R.; Dunn, B.; Gogotsi, Y. Multidimensional materials and device architectures for future hybrid energy storage. Nat. Commun. 2016, 7, No. 12647.

(3) Liu, C.; Neale, Z. G.; Cao, G. Understanding electrochemical potentials of cathode materials in rechargeable batteries. Mater. Today 2016, 19, 109-123.

(4) Wang, Z.; Wang, D.; Zou, Z.; Song, T.; Ni, D.; Li, Z.; Shao, X.; Yin, W.; Wang, Y.; Luo, W.; Wu, M.; Avdeev, M.; Xu, B.; Shi, S.; Ouyang, C.; Chen, L. Efficient potential-tuning strategy through ptype doping for designing cathodes with ultrahigh energy density. Natl. Sci. Rev. 2020, 7, 1768-1775.

(5) Liu, T.; Kim, K. C.; Kavian, R.; Jang, S. S.; Lee, S. W. Highdensity lithium-ion energy storage utilizing the surface redox reactions in folded graphene films. Chem. Mater. 2015, 27, 3291-3298.

(6) Zhong, X.; Wei, Y.; Guo, Y.; Cui, C.; Zhai, T.; Li, H. Double the energy storage of hard carbon anode for Li-ion batteries via a simple blending strategy. Electrochim. Acta 2020, 336, No. 135729.

(7) Goodenough, J. B.; Park, K.-S. The Li-ion rechargeable battery: a perspective. J. Am. Chem. Soc. 2013, 135, 1167-1176.

(8) Manthiram, A. A reflection on lithium-ion battery cathode chemistry. Nat. Commun. 2020, 11, No. 1550.

(9) Park, J.-S.; Kang, Y. C. Uniquely structured Sb nanoparticleembedded carbon/reduced graphene oxide composite shell with empty voids for high performance sodium-ion storage. Chem. Eng. J. 2019, 373, 227-237.

(10) Rajagopalan, R.; Tang, Y.; Ji, X.; Jia, C.; Wang, H. Advancements and Challenges in Potassium Ion Batteries: A Comprehensive Review. Adv. Funct. Mater. 2020, 30, No. 1909486.

(11) Niu, J.; Zhang, Z.; Aurbach, D. Alloy Anode Materials for Rechargeable $\mathrm{Mg}$ Ion Batteries. Adv. Energy Mater. 2020, 10, No. 2000697.

(12) Guo, Z.; Zhao, S.; Li, T.; Su, D.; Guo, S.; Wang, G. Recent Advances in Rechargeable Magnesium-Based Batteries for HighEfficiency Energy Storage. Adv. Energy Mater. 2020, 10, No. 1903591.

(13) Noori, A.; El-Kady, M. F.; Rahmanifar, M. S.; Kaner, R. B.; Mousavi, M. F. Towards establishing standard performance metrics for batteries, supercapacitors and beyond. Chem. Soc. Rev. 2019, 48, $1272-1341$.
(14) Aslam, M. K.; Niu, Y.; Xu, M. MXenes for Non-Lithium-Ion $(\mathrm{Na}, \mathrm{K}, \mathrm{Ca}, \mathrm{Mg}$, and $\mathrm{Al})$ Batteries and Supercapacitors. Adv. Energy Mater. 2021, 11, No. 2000681.

(15) Khossossi, N.; Singh, D.; Ainane, A.; Ahuja, R. Recent progress of defect chemistry on $2 \mathrm{D}$ materials for advanced battery anodes. Chem. - Asian J. 2020, 15, 3390-3404.

(16) Wang, D.-Y.; Wei, C.-Y.; Lin, M.-C.; Pan, C.-J.; Chou, H.-L.; Chen, H.-A.; Gong, M.; Wu, Y.; Yuan, C.; Angell, M.; Yu-Ju, H.; YuHsun, C.; Cheng-Yen, W.; Chun-Wei, C.; Bing-Joe, H.; Chia-Chun, C.; Hongie, D. Advanced rechargeable aluminium ion battery with a high-quality natural graphite cathode. Nat. Commun. 2017, 8, No. 14283.

(17) Xie, Y.; Dall'Agnese, Y.; Naguib, M.; Gogotsi, Y.; Barsoum, M. W.; Zhuang, H. L.; Kent, P. R. Prediction and characterization of MXene nanosheet anodes for non-lithium-ion batteries. ACS Nano 2014, 8, 9606-9615.

(18) Choi, J. W.; Aurbach, D. Promise and reality of post-lithium-ion batteries with high energy densities. Nat. Rev. Mater. 2016, 1, No. 16013.

(19) Liu, R.-S.; Mustarelli, P. Electrode Materials for Lithium and Post-Lithium Rechargeable Batteries. Front. Mater. 2020, 7, No. 48.

(20) Zhuang, Y.; Zou, Z.; Lu, B.; Li, Y.; Wang, D.; Avdeev, M.; Shi, $S$. Understanding the Li diffusion mechanism and positive effect of current collector volume expansion in anode free batteries. Chin. Phys. B 2020, 29, No. 068202.

(21) Xu, G.-L.; Amine, R.; Xu, Y.-F.; Liu, J.; Gim, J.; Ma, T.; Ren, Y.; Sun, C.-J.; Liu, Y.; Zhang, X.; Heald, S. M.; Solhy, A.; Saadoune, I.; Mattis, W. L.; Sun, S.-G.; Chen, Z.; Amine, K. Insights into the structural effects of layered cathode materials for high voltage sodiumion batteries. Energy Environ. Sci. 2017, 10, 1677-1693.

(22) Singh, D.; Shukla, V.; Khossossi, N.; Ainane, A.; Ahuja, R. Harnessing the unique properties of MXenes for advanced rechargeable batteries. J. Phys.: Energy 2020, 3, No. 012005.

(23) Zhao, C.; Yao, Z.; Zhou, D.; Jiang, L.; Wang, J.; Murzin, V.; Lu, Y.; Bai, X.; Aspuru-Guzik, A.; Chen, L.; Hu, Y.-S. Constructing NaIon Cathodes via Alkali-Site Substitution. Adv. Funct. Mater. 2020, 30, No. 1910840.

(24) Tang, Y.; Li, W.; Feng, P.; Zhou, M.; Wang, K.; Wang, Y.; Zaghib, K.; Jiang, K. High-Performance Manganese Hexacyanoferrate with Cubic Structure as Superior Cathode Material for Sodium-Ion Batteries. Adv. Funct. Mater. 2020, 30, No. 1908754.

(25) Hosaka, T.; Kubota, K.; Hameed, A. S.; Komaba, S. Research development on K-ion batteries. Chem. Rev. 2020, 120, 6358-6466.

(26) Alfaruqi, M. H.; Kim, S.; Park, S.; Lee, S.; Lee, J.; Hwang, J.-Y.; Sun, Y.-K.; Kim, J. Density Functional Theory Investigation of Mixed Transition Metals in Olivine and Tavorite Cathode Materials for LiIon Batteries. ACS Appl. Mater. Interfaces 2020, 12, 16376-16386.

(27) Guan, P.; Zhou, L.; Yu, Z.; Sun, Y.; Liu, Y.; Wu, F.; Jiang, Y.; $\mathrm{Chu}, \mathrm{D}$. Recent progress of surface coating on cathode materials for high-performance lithium-ion batteries. J. Energy Chem. 2020, 43, 220-235.

(28) Zhang, X.; He, Q.; Xu, X.; Xiong, T.; Xiao, Z.; Meng, J.; Wang, X.; Wu, L.; Chen, J.; Mai, L. Insights into the Storage Mechanism of Layered VS2 Cathode in Alkali Metal-Ion Batteries. Adv. Energy Mater. 2020, No. 1904118.

(29) Khossossi, N.; Shukla, V.; Benhouria, Y.; Essaoudi, I.; Ainane, A.; Ahuja, R.; Babu, G.; Ajayan, P. M. Exploring the Possibility of $\beta$ Phase Arsenic-Phosphorus Polymorph Monolayer as Anode Materials for Sodium-Ion Batteries. Adv. Theory Simul. 2020, 3, No. 2000023.

(30) Liu, D.; Liu, Z.; Li, X.; Xie, W.; Wang, Q.; Liu, Q.; Fu, Y.; He, D. Group IVA element ( $\mathrm{Si}, \mathrm{Ge}, \mathrm{Sn})$-based alloying/dealloying anodes as negative electrodes for full-cell lithium-ion batteries. Small 2017, 13, No. 1702000.

(31) Tian, H.; Xin, F.; Wang, X.; He, W.; Han, W. High capacity group-IV elements $(\mathrm{Si}, \mathrm{Ge}, \mathrm{Sn})$ based anodes for lithium-ion batteries. J. Materiomics 2015, 1, 153-169.

(32) Xiong, B.-Q.; Zhou, X.; Xu, G.-L.; Liu, Y.; Zhu, L.; Hu, Y.; Shen, S.-Y.; Hong, Y.-H.; Wan, S.-C.; Liu, X.-C.; Liu, X.; Chen, S.; Huang, L.; Sun, S.-G.; Amine, K.; Ke, F.-S. Boosting Superior Lithium 
Storage Performance of Alloy-Based Anode Materials via Ultraconformal $\mathrm{Sb}$ Coating-Derived Favorable Solid-Electrolyte Interphase. Adv. Energy Mater. 2020, 10, No. 1903186.

(33) Loaiza, L. C.; Monconduit, L.; Seznec, V. Si and Ge-Based Anode Materials for Li-, Na-, and K-Ion Batteries: A Perspective from Structure to Electrochemical Mechanism. Small 2020, 16, No. 1905260.

(34) Nzabahimana, J.; Liu, Z.; Guo, S.; Wang, L.; Hu, X. Top-down synthesis of silicon/carbon composite anode materials for lithium-ion batteries: mechanical milling and etching. ChemSusChem 2020, 13, 1923-1946.

(35) Goriparti, S.; Miele, E.; De Angelis, F.; Di Fabrizio, E.; Zaccaria, R. P.; Capiglia, C. Review on recent progress of nanostructured anode materials for Li-ion batteries. J. Power Sources 2014, 257, 421-443.

(36) Liu, J.; Wang, S.; Sun, Q. All-carbon-based porous topological semimetal for Li-ion battery anode material. Proc. Natl. Acad. Sci. U.S.A. 2017, 114, 651-656.

(37) Khossossi, N.; Banerjee, A.; Essaoudi, I.; Ainane, A.; Jena, P.; Ahuja, R. Thermodynamics and kinetics of $2 \mathrm{D}$ g-GeC monolayer as an anode materials for $\mathrm{Li} / \mathrm{Na}$-ion batteries. J. Power Sources 2021, 485, No. 229318.

(38) Reddy, M.; Subba Rao, G.; Chowdari, B. Metal oxides and oxysalts as anode materials for $\mathrm{Li}$ ion batteries. Chem. Rev. 2013, 113, 5364-5457.

(39) Zhang, P.; Wang, F.; Yu, M.; Zhuang, X.; Feng, X. Twodimensional materials for miniaturized energy storage devices: from individual devices to smart integrated systems. Chem. Soc. Rev. 2018, 47, 7426-7451.

(40) Khossossi, N.; Panda, P. K.; Singh, D.; Shukla, V.; Mishra, Y. K.; Essaoudi, I.; Ainane, A.; Ahuja, R. Rational Design of 2D h-BAs Monolayer as Advanced Sulfur Host for High Energy Density Li-S Batteries. ACS Appl. Energy Mater. 2020, 3, 7306-7317.

(41) Han, X.; Liu, C.; Sun, J.; Sendek, A. D.; Yang, W. Density functional theory calculations for evaluation of phosphorene as a potential anode material for magnesium batteries. RSC Adv. 2018, 8, 7196-7204

(42) Sheng, K.; Yuan, H.-K.; Chen, H.; Wang, Z.-Y. Adsorption of single alkali-metal atoms $(\mathrm{Li}, \mathrm{Na}, \mathrm{K})$ over the edge-passivated zigzag blue phosphorene nanoribbons. J. Phys. Chem. Solids 2020, No. 109623.

(43) Barik, G.; Pal, S. Energy gap-modulated blue phosphorene as flexible anodes for lithium-and sodium-ion batteries. J. Phys. Chem. C 2019, 123, 2808-2819.

(44) Benzidi, H.; Lakhal, M.; Garara, M.; Abdellaoui, M.; Benyoussef, A.; Mounkachi, O.; et al. Arsenene monolayer as an outstanding anode material for $(\mathrm{Li} / \mathrm{Na} / \mathrm{Mg})$-ion batteries: density functional theory. Phys. Chem. Chem. Phys. 2019, 21, 19951-19962.

(45) Boukhvalov, D.; Rudenko, A.; Prishchenko, D.; Mazurenko, V.; Katsnelson, M. Chemical modifications and stability of phosphorene with impurities: a first principles study. Phys. Chem. Chem. Phys. 2015, 17, 15209-15217.

(46) Ye, X.-J.; Zhu, G.-L.; Liu, J.; Liu, C.-S.; Yan, X.-H. Monolayer, bilayer, and heterostructure arsenene as potential anode materials for magnesium-ion batteries: a first-principles study. J. Phys. Chem. C 2019, 123, 15777-15786.

(47) Kamal, C.; Ezawa, M. Arsenene: Two-dimensional buckled and puckered honeycomb arsenic systems. Phys. Rev. B 2015, 91, No. 085423.

(48) Liu, B.; Köpf, M.; Abbas, A. N.; Wang, X.; Guo, Q.; Jia, Y.; Xia, F.; Weihrich, R.; Bachhuber, F.; Pielnhofer, F.; Wang, H.; Dhall, R.; Cronin, S. B.; Ge, M.; Fang, X.; Nilges, T.; Zhou, C. Black arsenicphosphorus: layered anisotropic infrared semiconductors with highly tunable compositions and properties. Adv. Mater. 2015, 27, 44234429.

(49) Long, M.; Gao, A.; Wang, P.; Xia, H.; Ott, C.; Pan, C.; Fu, Y.; Liu, E.; Chen, X.; Lu, W.; Tom, N.; Xu, J.; Wang, X.; Hu, W.; Miao, F. Room temperature high-detectivity mid-infrared photodetectors based on black arsenic phosphorus. Sci. Adv. 2017, 3, No. e1700589.
(50) Karki, B.; Rajapakse, M.; Sumanasekera, G. U.; Jasinski, J. B. Structural and Thermoelectric Properties of Black ArsenicPhosphorus. ACS Appl. Energy Mater. 2020, 3, 8543-8551.

(51) Young, E. P.; Park, J.; Bai, T.; Choi, C.; DeBlock, R. H.; Lange, M.; Poust, S.; Tice, J.; Cheung, C.; Dunn, B. S.; Goorsky, M. S.; Ozolinš, V.; Streit, D. C.; Gambin, V. Wafer-scale black arsenicphosphorus thin-film synthesis validated with density functional perturbation theory predictions. ACS Appl. Nano Mater. 2018, 1, 4737-4745.

(52) Luxa, J.; Bouša, D.; Zoller, F.; Fattakhova-Rohlfing, D.; Sofer, Z. Black phosphorus-arsenic alloys for lithium ion batteries. FlatChem 2020, 19, No. 100143.

(53) Hou, Y.; Ma, S.; Liu, Q.; Zhang, S.; Chu, Y.; Hao, X.; Han, B.; $\mathrm{Xu}, \mathrm{B}$. 2D black arsenic phosphorus and its application for anodes of lithium ion batteries. CrystEngComm 2020, 22, 8228-8235.

(54) Li, Y.; Chen, X. Dirac fermions in blue-phosphorus. 2D Mater. 2014, 1, No. 031002.

(55) Xie, M.; Zhang, S.; Cai, B.; Huang, Y.; Zou, Y.; Guo, B.; Gu, Y.; Zeng, H. A promising two-dimensional solar cell donor: Black arsenic-phosphorus monolayer with $1.54 \mathrm{eV}$ direct bandgap and mobility exceeding 14,000 cm2 V- $1 \mathrm{~s}-1$. Nano Energy 2016, 28, 433439.

(56) Qin, G.; Yan, Q.-B.; Qin, Z.; Yue, S.-Y.; Hu, M.; Su, G. Anisotropic intrinsic lattice thermal conductivity of phosphorene from first principles. Phys. Chem. Chem. Phys. 2015, 17, 4854-4858.

(57) Zhang, Y.; Wu, Z.-F.; Gao, P.-F.; Fang, D.-Q.; Zhang, E.-H.; Zhang, S.-L. Structural, elastic, electronic, and optical properties of the tricycle-like phosphorene. Phys. Chem. Chem. Phys. 2017, 19, 22452251.

(58) Zhu, Z.; Guan, J.; Tománek, D. Strain-induced metalsemiconductor transition in monolayers and bilayers of gray arsenic: a computational study. Phys. Rev. B 2015, 91, No. 161404.

(59) Jiang, H.; Zhao, T.; Ren, Y.; Zhang, R.; Wu, M. Ab initio prediction and characterization of phosphorene-like SiS and SiSe as anode materials for sodium-ion batteries. Sci. Bull. 2017, 62, 572-578.

(60) Li, F.; Qu, Y.; Zhao, M. Germanium sulfide nanosheet: a universal anode material for alkali metal ion batteries. J. Mater. Chem. A 2016, 4, 8905-8912.

(61) Sannyal, A.; Zhang, Z.; Gao, X.; Jang, J. Two-dimensional sheet of germanium selenide as an anode material for sodium and potassium ion batteries: first-principles simulation study. Comput. Mater. Sci. 2018, 154, 204-211.

(62) Jin, W.; Wang, Z.; Fu, Y. Q. Monolayer black phosphorus as potential anode materials for Mg-ion batteries. J. Mater. Sci. 2016, 51, $7355-7360$.

(63) Kulish, V. V.; Malyi, O. I.; Persson, C.; Wu, P. Adsorption of metal adatoms on single-layer phosphorene. Phys. Chem. Chem. Phys. 2015, 17, 992-1000.

(64) Wales, D. J.; Scheraga, H. A. Global optimization of clusters, crystals, and biomolecules. Science 1999, 285, 1368-1372.

(65) Zhao, S.; Kang, W.; Xue, J. The potential application of phosphorene as an anode material in Li-ion batteries. J. Mater. Chem. A 2014, 2, 19046-19052. 